\title{
Os J ogos Olímpicos e Paralímpicos Rio 2016: propostas para o esporte educacional, de participação e de rendimento
}

CDD. 20.ed. 796.05

796.48

http://dx.doi.org/10.1590/1807-55092015000300507

\author{
Suélen Barboza Eiras de CASTRO* \\ Doralice Lange de SOUZA*
}

*Setor de Ciências Biológicas, Universidade

Federal do Paraná

\section{Resumo}

Este trabalho visou identificar as propostas de legados para o esporte no Brasil a partir do Dossiê de Candidatura do Rio de Janeiro à Sede dos Jogos Olímpicos e Paralímpicos 2016 e Cadernos de Legado Rio 2016. A pesquisa se caracteriza como documental de cunho qualitativo. Selecionamos do Dossiê de Candidatura e dos Cadernos de Legado as propostas para o esporte que são apontadas como consequência da vinda dos Jogos. Para cada proposta buscamos identificar: 1) dimensão esportiva (educacional, participação e rendimento); 2) nível de alcance; 3) público-alvo; e 4) orçamento. Concluímos que dentre as diferentes dimensões do esporte, o de rendimento será privilegiado. São poucas as propostas que visam ampla disseminação da prática esportiva. A maioria das propostas se restringe à cidade do Rio de Janeiro e ao período pré-Jogos. 0 esporte educacional não é significativamente contemplado quando comparado às outras dimensões do esporte, o que contradiz a Política Nacional do Esporte e a Constituição Federal de 1988. Mais estudos são necessários para subsidiar o direcionamento das ações do governo no sentido de se garantir o acesso ao esporte como um direito de todos.

Palavras-chave: Olimpiadas; Megaevento esportivo; Legados esportivos; Políticas de esporte.

\section{Introdução}

Vivemos hoje um momento histórico interessante no âmbito esportivo no Brasil, uma vez que o país sediou e sediará grandes eventos como os XV Jogos Pan-americanos e Parapan-Americanos (Rio 2007), a Copa das Confederaçóes da FIFA (Brasil 2013), a Copa do Mundo de Futebol da FIFA (Brasil 2014) e os Jogos Olímpicos e Paralímpicos (Rio 2016). Estes eventos esportivos têm projetado o Brasil no cenário mundial e influenciado a formulação de políticas públicas para o esporte no país ${ }^{1}$.

Segundo a Constituição Federal de $1988^{2}$, existem três formas de manifestaçáo esportiva: educacional, participação e rendimento. Ainda de acordo com a Constituição, é dever do Estado fomentar o esporte como direito de cada um, observando-se "a destinação de recursos públicos para a promoção prioritária do desporto educacional e, em casos específicos, para a do desporto de alto rendimento"2.

A destinação prioritária de verbas ao esporte educacional descrita na Constituição Federal de 1988 diz respeito não somente aos órgãos públicos, mas a todas as entidades congregadas no Sistema Nacional do Desporto ${ }^{\text {a }}$. De acordo com artigo 14 da Lei 9.615/98 (Lei Pelé), todas as entidades congregadas no Sistema Nacional do Desporto estão submetidas ao disposto no inciso II do artigo 217 da Constituição Federal ${ }^{3}$.

Embora o esporte seja entendido como um direito e que a prioridade orçamentária deva ser para o esporte educacional, o termo "casos específicos" tem permitido uma inversão na destinação de recursos ao esporte e o lazer. Um exemplo disto pode ser verificado na Lei 10.264/2001 (Lei Agnelo Piva). A mesma prevê o repasse direto de $2 \%$ das loterias federais aos órgãos representativos do Movimento Olímpico no Brasil, ficando 85\% para o Comitê Olímpico do Brasil (COB) e 15\% para o Comitê Paralímpico Brasileiro (CPB). Deste total, 15\% deverá ser designado ao desporto educacional e universitário ${ }^{4}$. Desta forma, a destinação permanente de verbas para os "casos específicos" foi regulamentada e o esporte educacional acabou ficando em segundo 


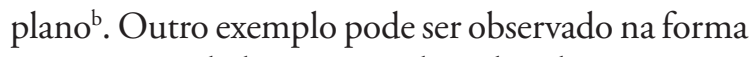
como se tem dado o repasse de verbas do governo ao esporte e ao lazer. Isto foi apreendido por AlmEIDA e MARCHI JÚNIOR ${ }^{5}$ ao mapear a aplicação de recursos públicos de 2004 a 2008 nestas áreas:

é possível identificar que o maior percentual investido (80\%) foi em esporte de alto rendimento no período observado, nas ações "Brasil no Esporte de Alto Rendimento - Brasil Campeão" e "Rumo ao Pan 2007". Se considerarmos que $11 \%$ é gasto com a administração dos programas, nas chamadas despesas de investimentos, vemos que resta menos de 9\% dos recursos para as ações de esporte escolar e participação (p.81).

Se considerarmos todos os eventos esportivos que o Brasil sediou e sediará nos próximos anos como "casos específicos", teremos ao longo de uma década o encaminhamento de verbas que supostamente deveriam ir para o esporte educacional sendo destinadas ao esporte de rendimento 5 .

Além de orientar o financiamento, a era de megaeventos em que estamos vivendo está orientando a própria formulação de políticas públicas para o esporte e o lazer no país. Isto pode ser observado no redirecionamento das açóes do Ministério do Esporte. A princípio este tinha suas açóes orientadas por um viés social voltado à democratização do esporte através de projetos sociais. Diante da realidade dos megaeventos o governo tem centrado suas açóes no sentido de buscar a projetar o país como uma potência no cenário esportivo mundial. Esta mudança de foco pode ser observada nas temáticas discutidas nas Conferências Nacionais do Esporte ${ }^{\mathrm{c}}(\mathrm{CNE})^{6}$.

A I e II CNE abordaram a temática "Esporte, Lazer e Desenvolvimento Humano" e "Construindo o Sistema Nacional de Esporte e Lazer", respectivamente. Em ambas as propostas para o esporte e o lazer estavam em conformidade com a Constituição Federal e buscavam contemplar as diversas práticas esportivas e de lazer e assegurar a democratização das mesmas. Também ficou estabelecido que as CNE deveriam ocorrer a cada dois anos. Após duas ediçóes cujos enfoques foram no desenvolvimento humano e democratização das atividades esportivas e de lazer, a III CNE, que ocorreu em 2010, rompeu com a periodicidade bienal e com as temáticas até então abordadas. $\mathrm{O}$ envolvimento do Brasil nos grandes eventos esportivos, que não havia entrado em pauta em nenhuma das ediçóes anteriores, tornou-se tema da III CNE $\mathrm{CN}^{9}$. Esta conferência teve como propósito a elaboração do "Plano Decenal de Esporte e Lazer", através do desenvolvimento de açốs em "10 pontos em 10 anos para Projetar o Brasil entre os 10 mais" ${ }^{\prime 10}$.
Os megaeventos esportivos no Brasil podem ser entendidos como "a principal política pública do Governo Lula náo apenas para o esporte, mas como uma política que transcende a jurisdição do Ministério do Esporte" ". Eles têm como propósito projetar o Brasil tanto no âmbito esportivo como no âmbito econômico e político ${ }^{1}$.

A organização destes eventos implica em um alto investimento por parte dos governos, o que tem gerado inúmeros questionamentos e debates nos meios acadêmicos e político, bem como na sociedade civil organizada. Vários são os benefícios alegados para a realização destes eventos, como, por exemplo, a construção de novas instalaçóes esportivas e gerais, revitalização urbana, crescimento do turismo, criação de novos empregos, promoçáo de valores culturais e educativos $^{11-12}$. Mas ainda que estes eventos possam promover lucros significativos, são muitas as contradiçóes existentes entre os ganhos financeiros e custos sociais e ambientais decorrentes dos mesmos ${ }^{11-14}$.

O Pan Rio 2007 é um bom exemplo disto. Ainda que seja apontado como determinante para a vitória da candidatura do Rio de Janeiro aos Jogos Olímpicos e Paralímpicos de 2016, ele náo apresentou grandes ganhos para a população carioca. De acordo com Bienenstein et al..$^{15}$,

Além da remoção de comunidades de baixa renda em "áreas de risco" [...] e da onerosa e questionável construção de um novo estádio na cidade, percebem-se operaçōes destinadas a favorecer a especulação imobiliária, beneficiar empreiteiras, promover a valorização fundiária, implantar moderna infraestrutura (telecomunicaçōes) em áreas nobres, aquecer o setor hoteleiro, assegurar a permanência de grupos políticos no Executivo local, fomentar o ufanismo urbano [...] e projetar internacionalmente a imagem da cidade (p.147).

Na ocasião da candidatura em 2002, o Pan-2007 estimava um gasto de $\mathrm{R} \$ 410$ milhóes. Em junho de 2007 , esse valor aumentou em $797 \%$, totalizando R \$ 3,7 bilhóes. Há também indicativos de superfaturamento e do náo provimento de alguns dos serviços acordados ${ }^{16}$. Considerando a insuficiência de legados sociais positivos decorrentes do Pan-2007, o governo brasileiro vem buscando provar que esta realidade será diferente no caso dos Jogos Olímpicos e Paralímpicos Rio $2016^{15}$. Algumas das proposiçôes de legados por parte do governo brasileiro são as de que os Jogos Rio 2016 irão promover uma transformação na "infraestrutura urbana, novas iniciativas ambientas, físicas e sociais, além de vantagens e oportunidade para todos"17 (p.18). Em termos de 
legados esportivos, dentre outras coisas, o governo afirma que buscará:

assegurar que, na vida posterior da cidade e do país, haja ampla disseminação da prática esportiva e da atividade física, notável avanço no desempenho olímpico brasileiro, eficiente qualificação de equipes técnicas, mais intercâmbio com outros países, pleno aproveitamento das grandes instalaçôes esportivas que os Jogos requerem e forte incremento da cadeia produtiva do esporte ${ }^{18}$ (p.8).

As propostas para o desenvolvimento do esporte apresentadas nos documentos oficiais dos Jogos Rio 2016 são apontadas como propostas que atendem tanto as determinaçóes do Comitê Olímpico Internacional (COI) quanto as diretrizes da Política Nacional do Esporte (PNE) ${ }^{17}$, que por sua vez apresenta o esporte como integrante do acervo cultural da humanidade e tem como um dos seus princípios o artigo 217 da Constituição Federal de $1988^{19}$.

Considerando as propostas relacionadas com os Jogos Rio 2016 e a legislação brasileira a respeito do esporte, este trabalho teve como objetivo identificar as proposiçóes de legado para o esporte no Brasil a partir das propostas de legados do Rio 2016 presentes no Dossiê de Candidatura do Rio de Janeiro à Sede dos Jogos Olímpicos e Paralímpicos 2016 e Cadernos de Legado Rio 2016.

\section{Método}

A pesquisa foi de caráter qualitativo e exploratório e teve como fontes o Dossiê de Candidatura do Rio de Janeiro à Sede dos Jogos Olímpicos e Paralímpicos $2016^{20-22}$ e os Cadernos de Legado Rio 2016 ${ }^{17-18,23}$. Selecionamos o Dossiê de Candidatura e os Cadernos de Legado por se tratarem de documentos de caráter oficial relacionados aos Jogos Rio 2016 que foram produzidos até o momento.

O Dossiê de Candidatura foi elaborado pelo Comitê de Candidatura Rio 2016 e entregue ao COI durante o processo de escolha da cidade sede dos Jogos Olímpicos e Paralímpicos de 2016. O Dossiê é composto de três volumes e descreve as condiçóes atuais e potenciais do Brasil, e mais especificamente, do Rio de Janeiro, para receber o evento. Ele foi construído para responder em que condiçóes o país atenderia as exigências do COI, numa perspectiva de convencimento para ganhar a disputa frente à outras localidades também candidatas a serem sede dos Jogos. Ele também apresenta os legados que se
Considerando que analisamos documentos oficiais, adotamos a concepção de esporte que aparece no artigo 217 da Constituição Federal de 1988², regulamentada pela lei n. 9.615/98 (Lei Pelé) ${ }^{3}$ :

I - desporto educacional, praticado nos sistemas de ensino e em formas assistemáticas de educação, evitando-se a seletividade, a hipercompetitividade de seus praticantes, com a finalidade de alcançar o desenvolvimento integral do indivíduo e a sua formação para o exercício da cidadania e a prática do lazer; II - desporto de participação, de modo voluntário, compreendendo as modalidades desportivas praticadas com a finalidade de contribuir para a integração dos praticantes na plenitude da vida social, na promoção da saúde e educação e na preservação do meio ambiente;

III - desporto de rendimento, praticado segundo normas gerais desta Lei e regras de prática desportiva, nacionais e internacionais, com a finalidade de obter resultados e integrar pessoas e comunidades do País e estas com as de outras naçôes.

Ao considerarmos as dimensóes acima, incluímos em nossa análise propostas que se relacionam com a atividade física de diferentes naturezas, como por exemplo, caminhadas, "jogging”, "trecking”, e com práticas de lazer e de promoção da saúde que envolvem movimento corporal.

pretende garantir para o país, a partir da preparação para o evento.

Após a escolha do Rio de Janeiro como cidade sede dos Jogos Olímpicos e Paralímpicos de 2016, o governo federal, através do Ministério do Esporte, lançou os Cadernos de Legado. Este documento foi designado como complementar ao Dossiê de Candidatura e apresenta o que o governo alega ser legado da realização dos Jogos no Brasil ${ }^{24}$. Eles foram endereçados ao $\mathrm{COI}$ e a diferentes setores da sociedade brasileira. São três os Cadernos de Legado: "Caderno Brasil, este é o país"18, "Caderno Legado Social" ${ }^{17} \mathrm{e}$ "Caderno Legado Urbano e Ambiental"23.

Considerando que estes documentos sistematizam as propostas de legados em função da realização dos Jogos Olímpicos e Paralímpicos no Brasil em diferentes áreas - esportiva, social, urbana e ambiental - o nosso primeiro procedimento de análise foi o de selecionar dos documentos tudo o que trata de "legados esportivos". Selecionamos destes materiais 
apenas as propostas para o esporte que são apontadas como consequência da vinda dos Jogos. Ou seja, propostas genéricas e que não foram vinculadas com a vinda dos Jogos não foram incluídas em nossa análise. Também não consideramos como proposições de legados esportivos as propostas que aparecem no Caderno de Legado "Brasil, este é o país" ${ }^{18}$. Este caderno é uma introdução aos outros cadernos e apresenta os legados esportivos de forma genérica.

Vale ressaltar que entendemos como legado tudo aquilo que foi criado ou modificado como consequência da realização do megaevento e que permanece após o mesmo, seja planejado ou não, positivo ou negativo, tangível ou intangível ${ }^{12}$. No entanto, considerando que o nosso objetivo foi o de levantar as propostas de legados para o esporte no país a partir dos documentos, nos focamos apenas nas proposiçóes que os mesmos apontavam como consequência dos Jogos.

Após levantarmos as propostas de legados esportivos e de agruparmos o que era comum em ambos os documentos, organizamos os dados em três QUADROS de acordo com as diferentes dimensóes do esporte: educacional, participação e de rendimento, conforme definido pelo artigo 217 da Constituição
Federal de 1988 e conforme a Lei n. 9.615 de 1998. As propostas que se encaixam em mais de um tipo de manifestação esportiva aparecem em mais de uma tabela. Para cada proposição buscamos identificar: 1) o seu nível de alcance; 2) o público-alvo; e 3) o orçamento previsto.

Vale a pena destacar que as informaçóes sobre os legados esportivos disponíveis nos documentos não são consistentes. Enquanto algumas propostas são bem detalhadas, outras são muito genéricas. Esta inconsistência se reflete nos dados que apresentaremos a seguir. Também ressaltamos que ao analisarmos os documentos, algumas propostas não estavam claras se estavam se repetindo ou não. Por exemplo, o Dossiê de Candidatura ${ }^{20}$ indica que serão construídas 29 instalaçóes esportivas de treinamento na cidade do Rio de Janeiro. Náo conseguimos identificar e não fica claro nos documentos se estas instalaçóes se relacionam com as estruturas do Centro Olímpico de Treinamento (COT). Outro exemplo é quando se diz no Dossiê de Candidatura ${ }^{18}$ que a infraestrutura esportiva da Barra será renovada. Neste caso, também não fica claro se as instalações esportivas do COT Barra estão contempladas neste item.

\section{Resultados e discussão}

Primeiramente apresentaremos os dados sintetizados em forma de QUADROS e a seguir faremos a discussão dos dados. Os mesmos foram organizados em três QUADROS. O primeiro se refere às propostas para o "esporte educacional". O segundo apresenta as propostas para o "esporte de participação". O QUADRO 3 apresenta as propostas para o "esporte de rendimento".

QUADRO 1- Propostas de legados para o esporte educacional.

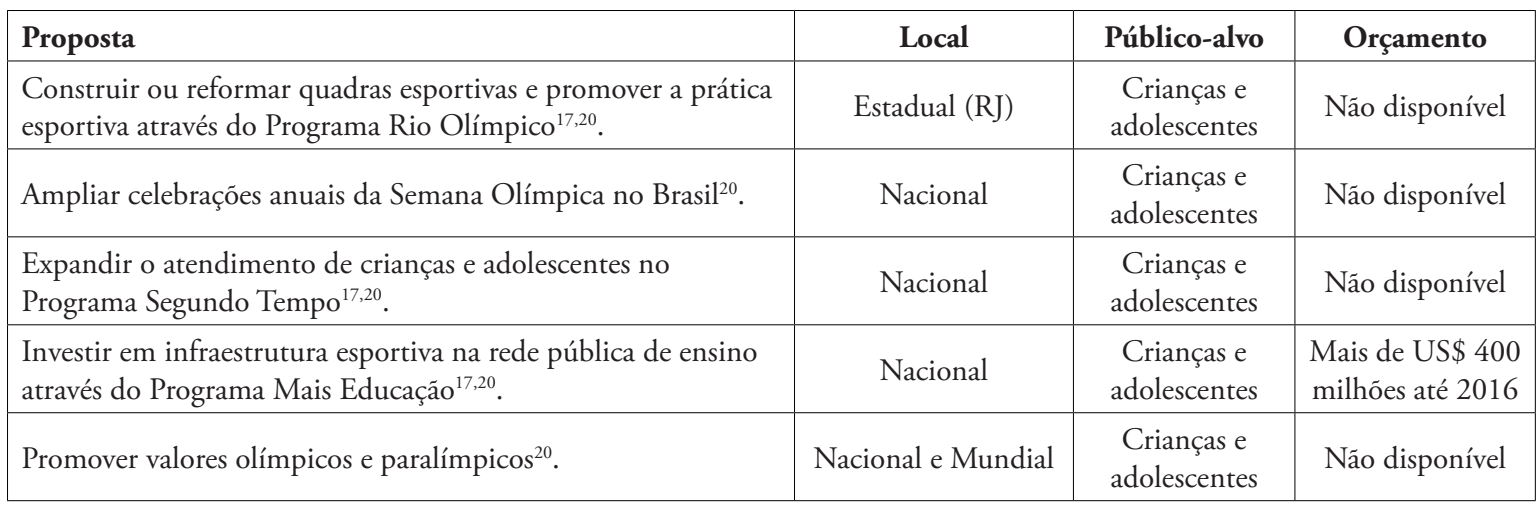


QUADRO 2 - Propostas de legados para o esporte de participação.

\begin{tabular}{|c|c|c|c|}
\hline Proposta & Local & Público-alvo & Orçamento \\
\hline $\begin{array}{l}\text { Construir ou reformar quadras esportivas e promover a prática } \\
\text { esportiva através do Programa Rio Olímpico }{ }^{17,20} \text {. }\end{array}$ & Estadual (RJ) & $\begin{array}{c}\text { Crianças e } \\
\text { adolescentes }\end{array}$ & Náo disponível. \\
\hline $\begin{array}{l}\text { Expandir os núcleos de esporte recreativo e de lazer do Programa } \\
\text { Esporte e Lazer da Cidade (PELC) }{ }^{17} \text {. }\end{array}$ & Nacional & $\begin{array}{c}\text { População } \\
\text { em geral } \\
\text { (Comunidades } \\
\text { de baixa renda) }\end{array}$ & Não disponível \\
\hline $\begin{array}{l}\text { Consolidar os Centros de Desenvolvimento de Estudos do Esporte } \\
\text { Recreativo e do Lazer (Rede CEDES) }{ }^{17} \text {. }\end{array}$ & Nacional & $\begin{array}{c}\text { Agentes e } \\
\text { gestores na área } \\
\text { esportiva }\end{array}$ & Não disponível \\
\hline Organizar demonstrações de esportes de rua ${ }^{20}$. & Não disponível & $\begin{array}{l}\text { População em } \\
\text { geral }\end{array}$ & Não disponível \\
\hline
\end{tabular}

\section{QUADRO 3 - Propostas de legados para o esporte de rendimento.}

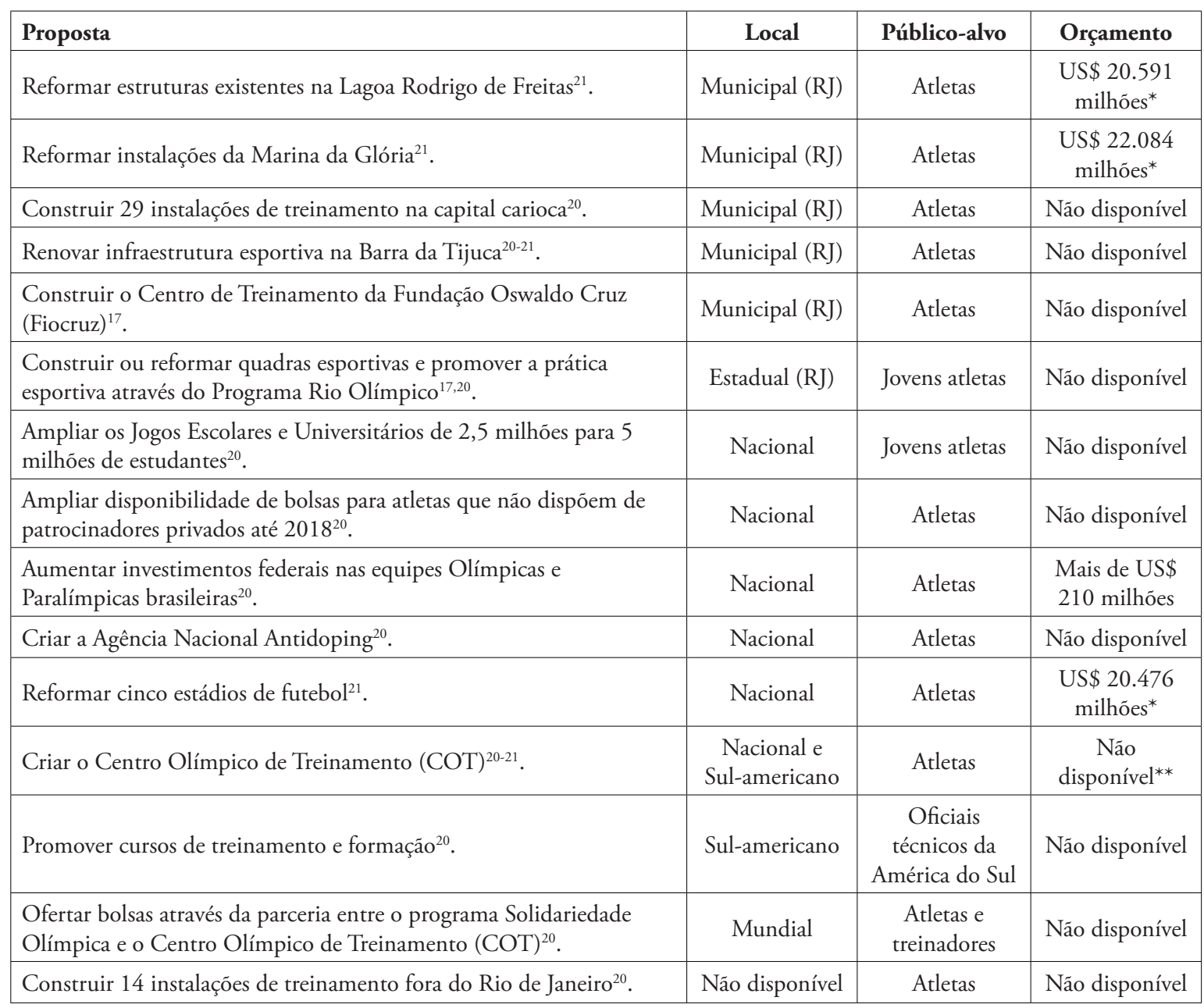

* Valores estimados para 2008.

** Ainda que no documento sejam disponibilizados os custos para instalações do Centro Olímpico de Treinamento (COT), o documento não indica e não fica claro qual o custo total para a construção do mesmo. 
Além das propostas apresentadas nos QUADROS 1,2 e 3, identificamos outras duas propostas a nível nacional que não apresentaram informações suficientes para que pudéssemos classificá-las como sendo específicas de uma ou outra dimensão esportiva. Uma delas tem como propósito aumentar investimentos em instalaçóes e programas esportivos através de incentivos fiscais de US\$ 80 milhões para US\$ 200 milhôes até $2016^{20}$. A outra tem como objetivo criar empregos na área de gestão esportiva ${ }^{20}$. Ambas estas propostas a princípio poderiam servir para qualquer tipo de esporte (educacional, participação ou rendimento).

\section{Esporte educacional}

A realização dos Jogos Rio 2016 é apontada como uma forma de impulsionar o esporte educacional no Brasi ${ }^{17}$. As propostas que contemplam este tipo de esporte nos documentos analisados são: Programa Segundo Tempo, Programa Mais Educação, Programa Rio Olímpico, Semana Olímpica e promoção de valores olímpicos e paralímpicos. O Programa Segundo Tempo funciona no período de contraturno escolar e tem como público alvo crianças e adolescentes entre seis e 17 anos, prioritariamente alunos de escolas públicas e/ou em áreas de vulnerabilidade social. Seu objetivo principal é o de "promover o desenvolvimento integral de crianças, adolescentes e jovens como fator de formação da cidadania e melhoria da qualidade de vida" por meio da democratização do acesso ao esporte educacional ${ }^{25}$. $\mathrm{O}$ atendimento deste programa será expandido de um milhão para três milhōes de crianças e adolescentes. Deste total, um milhão se concentrará na cidade do Rio de Janeiro ${ }^{17,20}$.

O Programa Mais Educação é um "programa de educação integral em tempo integral", que visa promover a educação de crianças e adolescentes através de atividades socioeducativas articuladas ao projeto pedagógico da escola. Tem como objetivos expandir o dia escolar e os espaços educacionais para além da escola e incorporar no currículo diferentes tipos de conhecimentos através de parcerias entre a escola e a comunidade ${ }^{26}$. Segundo os documentos analisados, o governo investirá mais de 400 milhôes de dólares até 2016 na construção de infraestrutura esportiva para o desenvolvimento de atividades do programa. Vale ressaltar que dentre as propostas para o esporte educacional, a única que possui orçamento definido é esta.

O Programa Rio Olímpico foi estabelecido pelo governo estadual do Rio de Janeiro e é desenvolvido através de parcerias com outros órgáos. O mesmo tem como propósito a disseminação da prática esportiva e visa atender "projetos de iniciação esportiva, esporte escolar, esporte social, esporte recreativo, atividade física e formação de atletas". Ele objetiva também "construir ou reformar quadras esportivas em bairros das periferias e contemplar o atendimento adequado a pessoas com deficiências" $(p .46)^{17}$. Este programa irá congregar iniciativas para promover o desenvolvimento de projetos e a construçáo de infraestrutura esportiva ${ }^{20}$.

A Semana Olímpica foi estabelecida pelo COB em 1998 e visa celebrar a criação do COI através de diversas atividades esportivas, educacionais e culturais envolvendo alunos e professores de diversas escolas do Brasil ${ }^{27}$. Esta semana será ampliada a partir de 2012 e envolverá diversas organizaçôes ligadas à atividades esportivas ${ }^{20}$.

A proposta para a promoçáo de valores olímpicos e paralímpicos apresentada no Dossiê de Candidatura ${ }^{20}$ visa atingir estudantes brasileiros e a juventude mundial. Em relaçáo aos estudantes brasileiros, este documento destaca o Programa de Educação Rio 2016. Este, por sua vez, engloba os projetos "Compartilhe sua Paixão", "Jovem Agência de Comunicação Rio 2016" e "Paixão pelo Rio". Ele engloba também a competição "Jovens Embaixadores" e conferências sobre esporte para jovens. O Dossiê também propóe mais financiamento para a formaçáo técnica de profissionais do esporte e o desenvolvimento de um programa pedagógico que contemple temáticas relacionadas ao esporte e a promoção de um estilo de vida saudável a ser disponibilizado para as escolas ${ }^{20}$.

Dentre as ações para a promoção de valores olímpicos e paralímpicos, apenas os projetos "Jovens Embaixadores" e "Compartilhe a sua Paixão" envolvem a prática da atividade física e apenas um projeto, "Compartilhe a sua Paixão", destina-se a estudantes do país como um todo. Os demais projetos estáo restritos ao município do Rio de Janeiro.

Nem o Dossiê de Candidatura e nem os Cadernos de Legado apresentam propostas para a promoção do esporte e de valores olímpicos nas aulas de Educação Física. Isto é lamentável, pois, conforme apontam vários autores ${ }^{28-31}$, são grandes as possibilidades de se relacionar eventos esportivos com processos educacionais. BETTI ${ }^{28}$, por exemplo, afirma que toda e qualquer modalidade esportiva pode ser tematizada pela Educação Física Escolar e que a transmissão televisionada dos Jogos Olímpicos pode-se tornar uma grande aliada. A transmissão televisionada também é apontada por HATZIDAKIs ${ }^{29}$ como uma aliada. De acordo com este autor, as 
situaçóes positivas e negativas dos megaeventos esportivos podem ser tematizadas e discutidas com os alunos, gerando inúmeras oportunidades de aprendizagem. RuBIO ${ }^{30}$, ao comentar sobre a educação olímpica ${ }^{\mathrm{e}}$, também ressalta a necessidade de se discutir as dimensóes éticas e morais das atividades culturais e corporais de megaeventos para além do espaço da educação formal. Estas possibilidades, no entanto, se dependerem dos documentos analisados, estão longe de serem bem exploradas.

Em relação às propostas para a promoção de valores olímpicos e paralímpicos para a juventude mundial, o Dossiê de Candidatura ${ }^{20}$ anuncia o desenvolvimento de iniciativas e programas com o COI, com o Comitê Paralímpico Internacional (IPC) e com outros parceiros. Ele também indica a expansão do programa "Inspiração Internacional" dos Jogos Londres 2012, elaboração de material pedagógico a ser distribuído no mundo todo, e o uso da rede "Olympics Live"g.

\section{Esporte de participação}

Em relação ao esporte de participação, os documentos propóem a criação e/ou ampliação de várias estruturas esportivas e de lazer, que por sua vez podem favorecer a participação da população como um todo em atividades esportivas. Os documentos citam a criação do Parque da Pedreira ${ }^{23}$, do Parque Ecológico do Vale do Pavuninha ${ }^{17}$, e do Parque Radical de Deodoro ${ }^{21}$. Eles também prometem a revitalização do Parque do Catumbi ${ }^{23}$. Estes parques terão espaços para atividades esportivas e de lazer como, por exemplo, para caminhadas e passeios ciclísticos. Os documentos também mencionam a ampliação da malha cicloviária do Rio de Janeiro e a revitalização de bairros e espaços públicos com o objetivo de promover espaços para o lazer e esporte. São estes o bairro de São Cristóvão ${ }^{25}$, a região do Sambódromo ${ }^{20,21,23}$, a Praia de Copacabana ${ }^{21}$ e o bairro da Barra da Tijuca ${ }^{20-21}$.

Além de falar sobre a criação/revitalização de estruturas, os documentos também mencionam alguns programas que podem promover o esporte de participação. Eles citam a ampliação do projeto de Vilas Olímpicas do governo municipal do Rio de Janeiro e a formação de Centros Integrados Profissionalizantes e Esportivos. Estes Centros ofertarão atividades esportivas e formação profissional e terão por objetivo atender 40 mil jovens por mês até 2016 advindos de comunidades de área de risco social ${ }^{17}$. Os documentos também citam o desenvolvimento de projetos esportivos e construção de infraestrutura esportiva através do Programa Rio Olímpico ${ }^{20}$. Também serão desenvolvidos programas para promover a atividade esportiva e hábitos de vida saudável no município do Rio de Janeiro. Estes programas terão o apoio do COT e serão realizados nas comunidades vizinhas do mesmo ${ }^{20}$.

Tanto as estruturas quanto os programas propostos nos documentos analisados se restringem ao município e Estado do Rio de Janeiro. Não existe nada proposto e planejado para o incentivo da prática de atividade física por parte da população como um todo além da ampliação do Programa de Esporte e Lazer da Cidade (PELC). Este programa é gerenciado pela Secretaria Nacional de Desenvolvimento do Esporte e do Lazer (SNDEL), do Ministério do Esporte e tem como objetivo democratizar o acesso ao esporte recreativo e ao lazer ${ }^{32}$. Os documentos não detalham como e onde as açóes deste programa irão ocorrer. A ampliação dos núcleos de esporte recreativo e de lazer do PELC se apresenta como a única proposta de programa para o esporte de participação a nível nacional. Este programa, no entanto, é voltado apenas para comunidades de baixa renda e atende um número restrito de pessoas.

Ainda que a promoção de um estilo de vida saudável seja citada várias vezes nos documentos analisados, estes não explicitam o que se entende por atividade física e/ou estilo de vida saudável. Eles também não apresentam nenhuma proposta de como se fará esta promoçáo. Aparentemente estas propostas partem do pressuposto de que a realização dos Jogos Rio 2016 por si só é capaz de inspirar a população para adotar um estilo de vida mais saudável. Todavia, conforme DonNELY $^{33}$ “esperar que os cidadãos sejam 'inspirados' sem mobilizar os recursos necessários para eles agirem naquela inspiração irá resultar em uma oportunidade desperdiçada e num investimento fracassado" (p.8, tradução nossa). Além disto, seria ingênuo pensar que o envolvimento da população com a atividade física vai aumentar a partir da realizaçáo de um megaevento esportivo ou que a simples construção de espaços irá garantir o envolvimento da população com prática esportiva $^{33}$. Faz-se necessário a construção de "uma cultura de acesso", e neste sentido, a escola poderia desempenhar um papel fundamental ${ }^{34}$. $\mathrm{O}$ cidadáo necessita também de condiçóes concretas para frequentar estes espaços, como por exemplo, nutrição adequada, tempo de lazer, segurança, transporte, etc. Ele também precisa de orientação para que possa fazer as práticas de forma adequada.

Os documentos também apontam para a organização de demonstrações de esportes de rua, como o 
"skate", o basquetebol de rua, o rapel, o "parkour" e a capoeira, através do festival "A Paixão em Movimento" ${ }^{20}$. Os mesmos, no entanto, não especificam a abrangência e os orçamentos para isto.

\section{Esporte de rendimento}

Em decorrência dos Jogos Olímpicos e Paralímpicos no Rio de Janeiro, os documentos indicam a construção e/ou reforma de várias instalações esportivas no município. As instalaçōes da Lagoa Rodrigo de Freitas, local das provas de remo e de canoagem (velocidade), e da Marina da Glória, local das provas de Vela, passarão por reformas. Além disso, cinco estádios de futebol - João Havelange (Rio de Janeiro), Mineirão (Belo Horizonte), Mané Garrincha (Brasília), Fonte Nova (Salvador) e Morumbi (São Paulo) - serão reformados. As reformas destes estádios estão relacionadas também com a Copa do Mundo de Futebol da FIFA de 2014. Os documentos também indicam a renovação da infraestrutura esportiva na Barra da Tijuca, bem como a construção de 29 instalaçóes de treinamento na cidade do Rio de Janeiro e de 14 instalaçóes esportivas fora do município. Os mesmos, no entanto, não apresentam maiores detalhes sobre as propostas. Todas as reformas e/ou construçôes de instalaçóes esportivas são consideradas como oportunidades para a promoção e desenvolvimento dos esportes nelas praticados ${ }^{21}$.

Algumas das instalaçóes esportivas para os Jogos Rio 2016 serão agrupadas e formarão o COT Barra e o COT Deodoro. O COT Barra englobará as instalações do basquetebol, handebol, lutas, tênis, hóquei, pólo aquático, saltos ornamentais, ciclismo (pista), natação e nado sincronizado. O COT Deodoro envolverá as instalaçóes do ciclismo (BMX e "Mountain Bike"), canoagem ("slalom"), hipismo, tiro, esgrima e pentatlo. Além disso, o COT, em parceria com o Programa Solidariedade Olímpica ${ }^{\text {h, }}$ irá ofertas bolsas a atletas e treinadores de fora do Brasil que não tenham acesso a programas de apoio e treinamento ${ }^{20}$. Segundo os documentos, após os Jogos, o COT será utilizado como local de treinamento, e no caso do Parque Radical de Deodoro, como local para atividades de lazer ${ }^{21}$.

O COT é considerado o "projeto de legado mais significativo da candidatura do Rio 2016" no Dossiê de Candidatura ${ }^{23}$. Paradoxalmente, ele não é mencionado em nenhum momento nos Cadernos de Legado, o que também acontece no caso de outras propostas.

Os documentos também mencionam a construção do Centro de Treinamento da Fundação
Oswaldo Cruz (Fiocruz). Este Centro envolverá várias instalações esportivas e um centro de avaliação e acompanhamento de atletas. Ele terá como meta a descoberta e aprimoramento de talentos olímpicos ${ }^{17}$. A formação de atletas também será contemplada através do desenvolvimento do Programa Rio Olímpico.

O esporte de rendimento será também incentivado através da expansão de bolsas para 11 mil atletas que não dispóem de patrocinadores privados até $2018 \mathrm{e}$ para o aumento para mais de US\$ 210 milhões de investimentos nas equipes olímpicas e paralímpicas do país ${ }^{20}$. Ele também será favorecido através da ampliação dos Jogos Escolares e Universitários de 2,5 milhóes para cinco milhóes de estudantes. Embora os jogos estejam vinculados ao sistema escolar, eles visam a competição de alto nível e estão sob a responsabilidade da Secretaria Nacional do Esporte de Alto Rendimento do Ministério do Esporte.

O esporte de rendimento é contemplado nos documentos por uma variedade de propostas. Estas englobam desde a criação de centros de treinamento e infraestruturas esportivas, até bolsas para atletas, cursos para oficiais técnicos, investimentos em equipes olímpicas e paralímpicas, oferta de projetos esportivos para crianças e adolescentes através do programa Rio Olímpico e construção da agência Nacional "Antidoping". As propostas também atingem os diversos níveis de abrangência (municipal, estadual, nacional e mundial) e de público-alvo (crianças, jovens e adultos). Da mesma forma que no caso dos outros tipos de manifestação do esporte, nem todas as propostas possuem orçamento e planejamento de açóes. As únicas propostas com certo nível de detalhamento quanto ao orçamento são aquelas que dizem respeito à infraestrutura esportiva necessária aos Jogos Olímpicos e Paralímpicos.

Nenhum dos documentos explicita ações específicas para o esporte paralímpico, a não ser uma afirmação genérica de que haverá investimento federal nas equipes paralímpicas brasileiras. Não se tem como saber, a partir dos documentos, até que ponto e de que forma o esporte paralímpico será favorecido.

A falta de consistência e detalhamento das propostas de legados para o esporte no Brasil nos documentos analisados dificultou a nossa análise. Mas mesmo diante desta dificuldade pudemos chegar às seguintes conclusóes: 1) São poucas as propostas de programas que visam incentivar a prática esportiva $\mathrm{e}$ ampliar o repertório de práticas esportivas por parte de população como um todo. Grande parte das propostas de estruturas e programas está concentrada 
na cidade do Rio de Janeiro; 2) A maior parte do planejamento se restringe ao que será feito antes dos Jogos; 3) Náo existem propostas para o incentivo do esporte educacional via Educação Física escolar; 4) Existe uma lacuna no que diz respeito ao planejamento orçamentário para inúmeras propostas de legados, principalmente as propostas relacionadas ao esporte de participação e educacional; 5) Considerando que existe um melhor planejamento, inclusive orçamentário, para o desenvolvimento do esporte de rendimento, este tipo de esporte provavelmente será favorecido em relação aos outros tipos de esporte.

Considerando a análise apresentada até então, concluímos que as propostas para o esporte no país não satisfazem o preceito da Constituição Federal e da Política Nacional do Esporte que determina que o mesmo é um direito de cada um e que o esporte educacional deve ter prioridade na destinação de recursos públicos frente aos outros tipos de esporte. A realização dos Jogos Olímpicos e Paralímpicos no Brasil está sendo tomada como um "caso específico" que tem permitido um maior enfoque no esporte de rendimento em detrimento das outras formas de manifestação do esporte.

Cinco anos se passaram desde que o Brasil ganhou a candidatura para os Jogos Olímpicos e Paralímpicos em 2016 e pouco se sabe sobre o que de fato o Estado tem feito para o desenvolvimento do esporte e do lazer no país. Estudos são necessários no sentido de acompanhar, avaliar e direcionar as ações do governo para que possamos concretizar os legados propostos para o desenvolvimento do esporte no país e para que possamos garantir que o mesmo seja encarado como um direito da população como um todo.

\section{Notas}

a. O Sistema Nacional do Desporto foi regulamentado pela lei 9.615/98 (Lei Pelé) e tem por objetivo a promoção e aprimoramento do desporto de rendimento. Ele reúne várias entidades, dentre as quais o Comitê Olímpico Brasileiro (COB) e o Comitê Paralímpico Brasileiro (CPB) têm destaque.

b. Para maiores informaçôes sobre as implicaçôes da Lei 10.264/2001, Agnelo Piva, consultar Almeida e MarCHI Junior ${ }^{35}$.

c. As Conferências Nacionais do Esporte (CNE) foram estabelecidas em 2004 através de um decreto presidencial e têm como objetivo envolver diversos segmentos da sociedade brasileira promovendo um espaço para a discussão na elaboração e deliberação de políticas públicas de esporte e lazer para o país a cada dois anos ${ }^{36}$.

d. Ao longo do texto, estaremos optando por utilizar os termos "Dossiê de Candidatura" e "Cadernos de Legado" para nos referirmos aos documentos analisados.

e. De acordo com TAvares et al. ${ }^{37}$, a Educação Olímpica "trata-se não propriamente de um conteúdo definido, mas, ajustando-se ao que preconiza a Lei de Diretrizes e Bases da Educação Nacional (Lei 9394/96), de um conjunto de atividades educativas de caráter multidisciplinar e transversal tendo como eixo integrador o esporte olímpico" (p.752).

f. O Programa "Inspiração Internacional" tem como objetivo usar o esporte como um meio para a transformação social, através do incentivo a prática esportiva entre jovens e qualificação de profissionais e professores de Educação Física que atuem em escolas e projetos esportivos ${ }^{38}$.

g. O Programa "Olympics Live" visa conectar jovens do mundo todo através de novas tecnologias. Este programa será financiado pelo Comitê Organizador dos Jogos Rio $2016^{20}$.

h. O Programa Solidariedade Olímpica é administrado pelo COI e tem como objetivo promover o apoio financeiro dos Comitês Olímpicos Nacionais. O Programa contempla quatro áreas: atletas, técnicos, gestão esportiva e promoção dos valores olímpicos ${ }^{39}$.

i. O Parque Radical de Deodoro sediará as instalaçôes de ciclismo (BMX e "Mountain Bike") e canoagem ("slalom"), e após os Jogos será utilizado tanto para o treinamento quanto para o lazer.

\section{Abstract}

The Olympic and Paralympic Games Rio 2016: proposals for educational, participation and elite sport

The goal of this study was to identify the promises for sport development in Brazil based on the Candidature File for Rio de Janeiro to Host the 2016 Olympic and Paralympic Games and the Legacy 
Notebooks Rio 2016. The research was documental and qualitative. We selected proposals for sport of the Candidature File and Legacy Books that are identified as a result of the Olympic Games. For each promise we identified: 1) dimension of sport (educational, participation and elite); 2) range level; 3) target public; and 4) budget. We concluded that elite sport will be privileged and that there is a lack of proposals for broad dissemination of sport. Most proposals are restricted to the city of Rio de Janeiro and to the pre-Games period. Educational sport is not significantly contemplated compared to the other dimensions of sport, which contradicts the National Sport Policy and the 1988 Brazilian Federal Constitution. More studies are needed to help directing actions in order to ensure sport for all as a legal right of all Brazilian citizens.

KeY WoRds: Olympics; Sport mega-events; Sport legacies; Sport policies.

\section{Referências}

1. Mascarenhas F, Silva AMS. A academia vai ao Olimpo: por uma política de ciência, tecnologia e inovação em esporte e lazer. Lect Educ Fís Deportes. 2012;17:171. Disponível em: http://www.efdeportes.com/efd171/politica-de-ciencia-em-esporte-e-lazer.html.

2. Brasil. Constituição, 1988. Constituição da República Federativa do Brasil [internet]. Brasília: Senado Federal;1988 [citado 19 dez. 2008]. Disponível em: http://www.senado.gov.br/legislacao/const/con1988/CON1988_05.10.1988/ CON1988.pdf.

3. Brasil. Lei n. 9.615 de 24 de março de 1998. Institui normas gerais sobre desporto e dá outras providências [internet]. Diário Oficial da República Federativa do Brasil. Brasília: 1998 [citado 19 ago. 2009]. Disponível em: http://www. planalto.gov.br/CCIVIL/Leis/L9615Compilada.html.

4. Brasil. Lei n.10.264 de 16 de julho de 2001. Acrescenta inciso e parágrafos ao artigo 56 da lei 9.615, de 24 de março de 1998, que institui normas gerais sobre desporto]. Diário Oficial da República Federativa do Brasil. Brasília: 2001 [citado 12 jan. 2012]. Disponível em: http://www6.senado.gov.br/legislacao/ListaPublicacoes.action?id=233173.

5. Almeida BS, Marchi Junior W. O financiamento dos programas federais de esporte e lazer no Brasil (2004 a 2008). Movimento. 2010;16:73-92. Disponível em: http://seer.ufrgs.br/Movimento/article/view/13103/10845.

6. Mascarenhas F. Megaeventos esportivos e educação física: alerta de tsunami. Movimento. 2012;18:39-67. Disponível em: http://seer.ufrgs.br/Movimento/article/view/25260/17340.

7. Brasil. I Conferência Nacional do Esporte: documento final. Brasília: Ministério do Esporte; 2004.

8. Brasil. II Conferência Nacional do Esporte: caderno de resoluçóes. Brasília: Ministério do Esporte; 2006.

9. Castelan LP. As conferências nacionais do esporte na configuraçáo da política esportiva e de lazer no governo Lula (2003-2010) [dissertação]. Campinas (SP): Universidade Estadual de Campinas; 2011.

10. Brasil. III Conferência Nacional do Esporte: texto básico. Brasília: Ministério do Esporte; 2010.

11. Malfas M, Theodoraki E, Houlihan B. Impacts of the Olympic Games as mega-events. Municipal Engineer. 2004;157:209220. Disponível em: http://epress.lib.uts.edu.au/dspace/bitstream/handle/2100/993/muen.157.3.209.49461. pdf?sequence $=1$.

12. Preuss H. Lasting effects of major sporting events. Idrottsforum.org [internet]. Mainz: Institute of Sport Science; 2006 [acesso em 13 jan. 2012]. Disponível em: http://www.idrottsforum.org/articles/preuss/preuss061213.pdf.

13. Horne J, Whanel G. Understanding the olympics. London: Routledge; 2012.

14. Whitson D, Horne J. Underestimated costs and overestimated benefits? Comparing the outcomes of sports mega-events in Canada and Japan. Sociol Rev. 2006;54:73-89.

15. Bienenstein G, Sánchez F, Cruz MCM, Guterman BC, Santos RRO, Souza RM. Megaeventos e metrópoles: insumos do Pan-2007 e perspectivas para as Olimpíadas de 2016. In: Mascarenhas G, Bienenstein G, Sánchez F, organizadores. O jogo continua: megaeventos esportivos e cidades. Rio de Janeiro: UERJ, 2011. p.123-61.

16. Torres D. Pan registrou caso de irregularidade e fiscalização frouxa [internet]. Folha de S.Paulo. 2009 out. 3 [citado 21 out. 2012]. Disponível em: http://wwwl.folha.uol.com.br/fsp/especial/fj0310200922.html.

17. Brasil. Ministério do Esporte. Caderno de Legado Social [internet]. Brasília: Ministério do Esporte; 2009 [citado 9 jun. 2011]. Disponível em: http://www.esporte.gov.br/arquivos/rio2016/cadernoLegadosSocial.pdf. 
18. Brasil. Ministério do Esporte. Caderno de Legado Brasil, este é o país [internet]. Brasília: Ministério do Esporte; 2009 [citado 9 jun. 2011]. Disponível em: http://www.esporte.gov.br/arquivos/rio2016/cadernoLegadosBrasil.pdf.

19. Brasil. Ministério do Esporte. Política Nacional do Esporte. Resolução n.5/Conselho Nacional do Esporte [internet]. 14 de junho de 2005 [citado 12 jan. 2012]. Disponível em: http://www.esporte.gov.br/arquivos/politicaNacional/ politicaNacionalCompleto.pdf.

20. Brasil. Dossiê de candidatura do Rio de Janeiro a sede dos Jogos Olímpicos e Paralímpicos de 2016 [internet]. 2009. v.1 [citado 10 jun. 2011]. Disponível em: http://www.rio2016.org/sites/default/files/parceiros/dossie_de_candidatura_v1.pdf.

21. Brasil. Dossiê de candidatura do Rio de Janeiro a sede dos Jogos Olímpicos e Paralímpicos de 2016 [internet]. 2009. v.2 [citado 10 jun. 2011]. Disponível em: http://www.rio2016.org/sites/default/files/parceiros/dossie_de_candidatura_v2.pdf.

22. Brasil. Dossiê de candidatura do Rio de Janeiro a sede dos Jogos Olímpicos e Paralímpicos de 2016 [internet]. 2009. v.3 [citado 10 jun. 2011]. Disponível em: http://www.rio2016.org/sites/default/files/parceiros/dossie_de_candidatura_v3.pdf.

23. Brasil. Ministério do Esporte. Caderno de Legado Urbano e Ambiental [internet]. 2009 [citado 10 jun. 2011]. Disponível em: http://www.esporte.gov.br/arquivos/rio2016/cadernoLegadosUrbanoAmbiental.pdf.

24. Brasil. Rio 2016[internet]. [citado 2011 jun. 10]. Disponível em: http://www.esporte.gov.br/snear/rio2016/default.jsp.

25. Brasil. Ministério do Esporte. Diretrizes do Programa Segundo Tempo 2011 [internet]. Brasília, 2011 [acesso em 2012 ago. 16]. Disponível em: http:/www.esporte.gov.br/arquivos/snee/segundoTempo/DiretrizesdoProgramaSegundoTempo.pdf.

26. Brasil. Ministério da Educação. Programa Mais Educação: gestão intersetorial no território. Brasília: Ministério da Educação/Secretaria de Educação Continuada, Alfabetização e Diversidade; 2009. (Série Mais Educação).

27. COB. Comitê Olímpico Brasileiro. Semana Olímpica [internet]. Rio de Janeiro: COB; 2012 [acesso 24 set. 2012]. Disponível em: http://www.cob.org.br/noticias-cob/cob-celebra-semana-olmpica-2012-em-todas-as-cinco-regies-do-brasil-com-atividades-esportivas-e-culturais-024404.

28. Betti M. Copa do Mundo e Jogos Olímpicos: inversionalidade e transversalidades na cultura esportiva e na educação física escolar. Motrivivência. 2009;21: 16-27. Disponível em: http://www.periodicos.ufsc.br/index.php/motrivivencia/ article/view/15540/14104.

29. Hatzidakis GS. Legado educacional dos Jogos Pan-Americanos e dos Jogos Parapan 2007: instumentalizando a escola. In: DaCosta LP, editor. Legados de megaeventos esportivos. Brasília: Ministério do Esporte; 2008. p.395-401.

30. Rubio K. O legado educativo dos megaeventos esportivos. Motrivivência 2009; 21:71-88. Disponível em: http://www. periodicos.ufsc.br/index.php/motrivivencia/article/view/15575.

31. Tavares O. Megaeventos esportivos. Movimento. 2011;17:11-35. Disponível em: http://seer.ufrgs.br/Movimento/ article/viewFile/23176/14689.

32. Brasil. Ministério do Esporte. Programa Esporte e Lazer na cidade [internet]. Brasília: Ministério do Esporte; 2012 [citado 13 dez. 2012]. Disponível em: http://www.esporte.gov.br/sndel/esporteLazer/default.jsp.

33. Donnelly P. Opportunity knocks!: increasing sport participation in canada as a result of success at the Vancouver Olympics. Toronto: Faculty of Kinesiology and Physical Education; 2008. (Centre for Sport Policy Studies Position Paper Series; 2).

34. Souza J, Marchi Junior W. Os “legados” dos megaeventos esportivos no Brasil: algumas notas e reflexóes. Motrivivência. 2010;22:245-55. Disponível em: http://www.periodicos.ufsc.br/index.php/motrivivencia/article/view/17115/15858.

35. Almeida BS, Marchi Junior, W. A relação governo federal e Comitê Olímpico Brasileiro com base na análise da Lei 10.264/2001 (Agnelo Piva) no período de 2005 a 2008. Pensar Prát. 2012;15:575-95. Disponível em: http://www. revistas.ufg.br/index.php/fef/article/view/15238/12079.

36. Brasil. Ministério do Esporte. Conferência Nacional do Esporte [internet]. Brasília: Ministério do Esporte; 2012 [citado 12 ago. 2012]. Disponível em: http://www.esporte.gov.br/conferencianacional/default.jsp.

37. Tavares O, Belém C, Godoy L, Turini M, Gomes M, Todt N. Estudos olímpicos, Academia Olímpica Brasileira e educação olímpica. In: Da Costa LP, organizador. Atlas do esporte no Brasil. Sprint: Rio de Janeiro; 2005. p.538.

38. Rio 2016. Rio 2016 vai ampliar o projeto social de Londres 2012 [internet]. Rio de Janeiro: 2010 [citado 13 fev. 2013]. Disponível em: http://www.rio2016.org/noticias/noticias/rio-2016-vai-ampliar-projeto-social-de-londres-2012.

39. COB. Comitê Olímpico Brasileiro. Solidariedade Olímpica [internet]. Rio de Janeiro: COB; 2013 [citado 13 fev. 2013]. Disponível em: http://www.cob.org.br/movimento-olimpico/solidariedade-olimpica. 


\section{Agradecimentos}

Agradecemos ao Programa Reuni pela bolsa de doutorado concedida a primeira autora.

Agradecemos também à Fundação Araucária pelo financiamento da pesquisa intitulada "Possíveis legados esportivos dos Jogos Olímpicos e Paraolímpicos Rio 2016: expectativas e propostas”, que possibilitou o desenvolvimento deste trabalho. Somos também gratas aos alunos envolvidos no referido projeto pelo auxílio na compilação dos dados.

Suelen Barboza Eiras de Castro Departamento de Educação Física

Setor de Ciências Biológicas Universidade Federal do Paraná

R. Coração de Maria, 92

80215-370 - Curitiba - PR - BRASIL

e-mail: sueleneiras@hotmail.com

Recebido para publicação: 21/ 02/ 2013

1a. Revisão: 12/03/2014

2a. Revisão: 23/ 09/2014

Aceito: 07/ 10/ 2014 